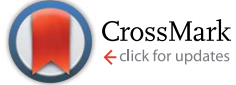

Cite this: J. Mater. Chem. A, 2015, 3, 4155

Received 15th October 2014

Accepted 13th November 2014

DOI: $10.1039 / \mathrm{c} 4 \mathrm{ta} 05523 \mathrm{c}$

www.rsc.org/MaterialsA

\section{Gradient dopant profiling and spectral utilization of monolithic thin-film silicon photoelectrochemical tandem devices for solar water splitting $\dagger$}

\author{
Lihao Han, ${ }^{\text {ac }}$ Ibadillah A. Digdaya, ${ }^{\text {b }}$ Thom W. F. Buijs, ${ }^{a}$ Fatwa F. Abdi,,$^{\text {b }}$ \\ Zhuangqun Huang, ${ }^{c}$ Rui Liu, ${ }^{c}$ Bernard Dam, ${ }^{c}$ Miro Zeman, ${ }^{a}$ Wilson A. Smith*b \\ and Arno H. M. Smets*a
}

\begin{abstract}
A cost-effective and earth-abundant photocathode based on hydrogenated amorphous silicon carbide (a-SiC:H) is demonstrated to split water into hydrogen and oxygen using solar energy. A monolithic a-SiC:H photoelectrochemical (PEC) cathode integrated with a hydrogenated amorphous silicon (a-SiC:H)/nano-crystalline silicon (nc-Si:H) double photovoltaic (PV) junction achieved a current density of $-5.1 \mathrm{~mA} \mathrm{~cm}^{-2}$ at $\mathrm{OV}$ versus the reversible hydrogen electrode. The a-SiC:H photocathode used no hydrogen-evolution catalyst and the high current density was obtained using gradient boron doping. The growth of high quality nc-Si:H PV junctions in combination with optimized spectral utilization was achieved using glass substrates with integrated micro-textured photonic structures. The performance of the PEC/PV cathode was analyzed by simulations using Advanced Semiconductor Analysis (ASA) software.
\end{abstract}

\section{Introduction}

Solar energy is by far the most abundant and sustainable energy source available on the earth. However, the implementation of photovoltaic (PV) technologies is limited by the periodic nature of the solar irradiance at a certain location and time. Thus we need to store solar energy in the form of a chemical fuel to be used when little or no solar irradiance is available. One promising method to store solar energy is to utilize sunlight to split water into hydrogen and oxygen using a photoelectrochemical (PEC) water-splitting device. Hydrogen is a carbon-free and high caloric energy carrier that can be used to produce electricity when recombined with $\mathrm{O}_{2}$ in a fuel cell. Thus the search for an ideal semiconductor electrode for PEC water splitting has become an important challenge to many researchers.

Currently, most solar-to-hydrogen conversion devices with efficiencies $\left(\eta_{\mathrm{STH}}\right)>1 \%$, have been achieved by hybrid device configurations, in which at least one PEC junction is combined with one or more PV junction(s). ${ }^{1-13}$ In 1998, Turner and

${ }^{a}$ Photovoltaic Materials and Devices (PVMD) Laboratory, Delft University of Technology, P.O. Box 5031, 2600 GA Delft, Netherlands. E-mail: L.Han@tudelft.nl; A.H.M.Smets@tudelft.nl

${ }^{b}$ Materials for Energy Conversion and Storage (MECS) Laboratory, Delft University of Technology, P.O. Box 5045, 2600 GA Delft, Netherlands.E-mail: W.Smith@tudelft.nl cJoint Center for Artificial Photosynthesis (JCAP), California Institute of Technology, Pasadena, California, 91125, USA

$\dagger$ Electronic supplementary information (ESI) available. See DOI: $10.1039 / \mathrm{c} 4 \mathrm{ta} 05523 \mathrm{c}$

‡. Current address: Institute for Solar Fuels, Helmholtz-Zentrum Berlin für Materialien und Energie Gmbh, Hahn-Meitner-Platz 1, 14109 Berlin, Germany.
Khaselev demonstrated a monolithic PEC/PV solar water-splitting device based on a $\mathrm{GaInP}_{2}$ photocathode and a GaAs PV junction, showing a $\eta_{\mathrm{STH}}$ of $12.4 \% .^{7}$ Three years later, Licht et al. showed a stacked multi-junction solar water-splitting device based on AlGaAs/Si with the reported $\eta_{\mathrm{STH}}$ of $18.3 \%{ }^{8}$ However, the device used scarce and expensive materials, as well as complex device architectures. In addition, some of these high performance devices have a limited stability in their electrolyte. These undesirable features are likely to hinder their large-scale applications for water splitting.

In the search for alternative earth-abundant materials, various PEC/PV junctions have been explored using stable metal-oxides such as doped tungsten trioxide $\left(\mathrm{WO}_{3}\right)$ or bismuth vanadate $\left(\mathrm{BiVO}_{4}\right)$ as photoelectrodes with silicon $(\mathrm{Si}){ }^{\mathbf{1 - 3 , 6 , 9 , 1 4 , 1 5}}$ To date, the highest reported $\eta_{\mathrm{STH}}$ of $5.2 \%$ for metal-oxidebased devices was achieved using a combination of a gradientdoped $\mathrm{W}-\mathrm{BiVO}_{4}$ photoanode with a double-junction micromorph silicon (a-Si:H/nc-Si:H) PV device. ${ }^{2}$ However, metaloxides generally have relatively large band gaps $(2.3-3 \mathrm{eV})$, which limits their $\eta_{\mathrm{STH}}$ values below $10 \%$.

Hydrogenated amorphous silicon carbide (a-SiC:H) is a more attractive alternative with a band gap that can be tuned between 1.8 and $2.3 \mathrm{eV}$ by varying the carbon concentration. ${ }^{\mathbf{1 6}}$ For example, a device with an $\mathrm{a}-\mathrm{Si}_{0.9} \mathrm{C}_{0.1}: \mathrm{H}$ absorption layer can theoretically generate $15 \mathrm{~mA} \mathrm{~cm}^{-2}\left(\eta_{\mathrm{STH}} \sim 18 \%\right)$ of an Air Mass (AM) 1.5 photocurrent based on its band gap energy of $2.0 \mathrm{eV}$. Furthermore, since doped a-SiC: $\mathrm{H}$ is widely used as a window layer in the solar cell industry, ${ }^{17-20}$ a full monolithic PEC/PV integration between a-SiC:H and thin-film silicon (TF-Si) PV junctions is practically feasible. The processing conditions of 
a-SiC:H PEC junctions are fully compatible with those of the TF-Si PV junctions since both can be deposited using a plasmaenhanced chemical vapor deposition (PECVD) technique. No deposition at high temperatures (only 170-200 ${ }^{\circ} \mathrm{C}$ ) or postannealing is necessary, in contrast to many metal-oxide photoelectrodes. ${ }^{3}$ In addition, TF-Si processing is highly scalable as already demonstrated by the TF transistor and PV industry. Finally, a-SiC: $\mathrm{H}$ is stable in an aqueous environment (even in a pH 0.3 acid), ${ }^{21,22}$ and both Si and $\mathrm{C}$ are non-toxic and earth-abundant materials.

Despite the advantages mentioned above, the PEC performance of a-SiC:H photocathodes reported in the literature to date is well below their theoretical potential. ${ }^{20,21,23-27}$ In 2007, Zhu et al. demonstrated a simple p/i a-SiC:H photocathode that was free of its native oxide and generated a photocurrent density of $\sim-0.6 \mathrm{~mA} \mathrm{~cm}^{-2}$ at $0 \mathrm{~V}$ versus the reversible hydrogen electrode ( $v s$. RHE).$^{20}$ Only at a negative bias of $-1.5 \mathrm{~V} v s$. RHE did the photocurrent density reach $\sim-7 \mathrm{~mA} \mathrm{~cm}^{-2}$, showing the large overpotential needed to drive the a-SiC:H photocathode to higher photocurrent densities. One of the main challenges for this material is therefore to reduce this overpotential, which originates from surface recombination, poor material quality and low charge carrier collection efficiency (sometimes noted as carrier separation efficiency). Other important challenges are the low catalytic performance and poor spectral utilization when a-SiC:H is used in a tandem configuration. One attempt to improve the low catalytic performance of a-SiC:H by placing metal or metal-oxide nanoparticles on the electrode surface has been reported. ${ }^{28}$ The photocurrent increased to $\sim-1.8 \mathrm{~mA} \mathrm{~cm}^{-2}$ at zero bias (two-electrode, vs. $\mathrm{RuO}_{2}$ counter electrode) using $\mathrm{Ru}-$ nanoparticles to catalyze the hydrogen evolution reaction (HER) on an a-SiC:H photocathode combined with a double-junction aSi:H solar cell. However, the current density was still an order of magnitude lower than the theoretical limit.

In this paper, we apply several methods to reduce the overpotential of an a-SiC:H based photocathode. First, the charge carrier collection is improved by introduction of gradient boron doping in the a-SiC:H PEC junction. We then achieve an anodic shift of the onset potential by the monolithic integration of TF-Si PV junctions. Finally we introduce state-of-the-art glass substrates with integrated micro-textured photonic structures for the PEC/PV hybrid cathodes to improve light collection. These substrates allow the processing of TF-Si PV junctions exhibiting dense and high electrical-grade nc-Si:H and facilitate high spectral utilization in the PEC and PV junctions.

We then explore three different monolithic PEC/PV cathode configurations based on TF-Si single and double PV junctions. Fig. 1 shows a schematic illustration of an a-SiC:H(PEC)/ nc-Si:H(PV)/nc-Si:H(PV) cathode together with a cross-sectional scanning electron microscope (SEM) image of the processed cathode. The balance between the anodic shift and the optimized spectral utilization of the PEC/PV configuration is also studied. Simulations of the spectral utilization of the PEC/PV cathodes using an in-house developed Advanced Semiconductor Analysis (ASA) software supports the experimentally observed anodic shifts and current densities. Finally, the stability of the silicon-based photocathodes under operation is demonstrated.

\section{Experimental}

\subsection{PECVD fabrication of photocathodes}

The a-SiC:H photocathodes were deposited using a radio frequency (RF-) PECVD multi-chamber tool. A $2.5 \mathrm{~cm} \times 10 \mathrm{~cm}$ Asahi VU-type substrate was heated at $170{ }^{\circ} \mathrm{C}$ during the deposition. The a-SiC:H(B) layer was deposited as the p-layer, decomposed from $\mathrm{SiH}_{4}, \mathrm{CH}_{4}$ and $\mathrm{B}_{2} \mathrm{H}_{6}$ diluted $\mathrm{H}_{2}$ gas flow under a controlled pressure. The gradient $\mathrm{B}$ doped " $\mathrm{p}-$ " layer was deposited by a programmed 10-step recipe in which a 2 sccm $\mathrm{B}_{2} \mathrm{H}_{6}$ diluted $\mathrm{H}_{2}$ gas flow rate was evenly reduced per 36 seconds from the processing conditions used for the initial p-layer until $0 \mathrm{sccm} \mathrm{B}_{2} \mathrm{H}_{6}$ gas flows corresponding to the typical i-layer processing conditions. $\mathrm{A}_{2}$ treatment at a low RF-power intensity was followed in the same chamber in order to improve the $\mathrm{p} / \mathrm{i}$ interface. The $\mathrm{i}$-type a-SiC: $\mathrm{H}$ (optimized as a- $\mathrm{Si}_{0.9} \mathrm{C}_{0.1}: \mathrm{H}$ in the rest of this paper, as discussed in the ESI Table S1, Fig. S1 and $\mathrm{S} 2 \dagger$ ) was deposited in another chamber specifically to avoid possible cross-contamination. After the a-SiC:H thin-films were synthesized, a stripe of $300 \mathrm{~nm}$ Al was coated on the pre-covered region of the sample as the front contact using a PROVAC evaporator in a rotation mode. The purpose of the $\mathrm{Al}$ stripe is to ensure the effective collection of the generated photocurrent.

\subsection{Glass with integrated micro-textured photonic structures and high quality nc-Si:H materials}

A $100 \mathrm{~nm}$ thick layer of an ITO film was sputtered on a piece of Corning glass with a size of $2.5 \mathrm{~cm} \times 10 \mathrm{~cm}$. The glass was then dipped into an acid solution (41\% $\mathrm{HF}: 50 \% \mathrm{H}_{2} \mathrm{O}_{2}: \mathrm{H}_{2} \mathrm{O}=$ $1: 2: 10$ volume ratio) for $45 \mathrm{~min}$. The ITO acted as the sacrificed layer for glass etching, and micro-textured features were formed. On the non-ITO-coated side, the etching rate was extremely slow and the glass surface remained flat. An AZO layer with a thickness of 1.5-1.8 $\mu \mathrm{m}$ was sputtered on the textured glass, followed by $0.5 \%$ diluted $\mathrm{HCl}$ acid etching for 40 seconds. Small features of a few hundreds of nanometers were created on the AZO layer, as shown by the tiny "bubble" structures in the microscopy image in Fig. S3 (ESI $\dagger$ ). A metal layer consisting of $30 \mathrm{~nm} \mathrm{Cr}$ and $100 \mathrm{~nm} \mathrm{Ag}$ was evaporated on the top of the modulated surface textured glass substrate as the back reflector. Before the deposition of TF-Si layers, an $80 \mathrm{~nm}$ thick AZO layer was sputtered on the $\mathrm{Ag}$ to improve the $\mathrm{Si} / \mathrm{metal}$ interface. The sample was then transferred into the same PECVD tool and heated to $170{ }^{\circ} \mathrm{C} .40 \mathrm{~nm}$ thick boron (B) doped nc-SiO $x: \mathrm{H}$ was used as the p-layer and $25 \mathrm{~nm}$ thick phosphorus (P) doped nc-SiO ${ }_{x}: \mathrm{H}$ was used as the n-layer in all photocathodes (A: a-SiC:H/ a-Si:H, B: a-SiC:H/a-Si:H/nc-Si:H and C: a-SiC:H/nc-Si:H/ nc-Si:H). In photocathode A, the bottom nc-Si:H i-layer is $3 \mu \mathrm{m}$, and the top nc-Si:H i-layer is $1 \mu \mathrm{m}$. In photocathode $\mathrm{B}$, the bottom nc-Si:H i-layer is also $3 \mu \mathrm{m}$, but the top a-Si:H i-layer is $0.3 \mu \mathrm{m}$. For the best performance of the double-junction cells, the i-nc-Si:H material deposition requires a high VHF (very-highfrequency) power $(40 \mathrm{~W})$. In photocathode $\mathrm{A}$, the a-Si:H i-layer is 


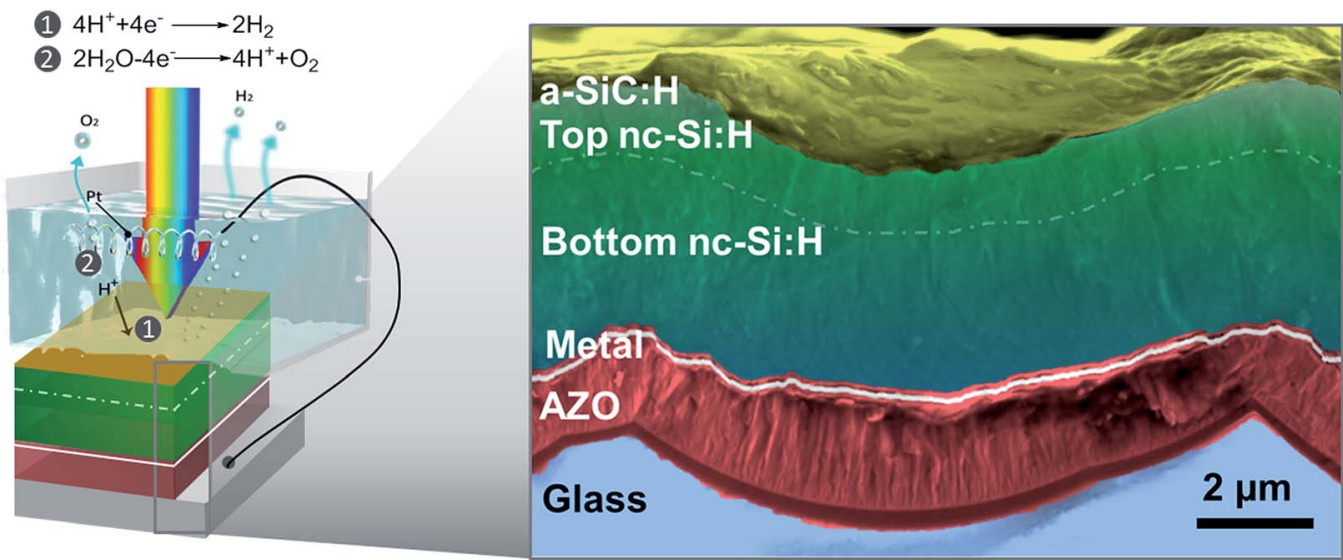

(a)

Fig. 1 A sketch illustration (a) and an SEM image (b) of the a-SiC:H photocathode integrated with nc-Si:H/nc-Si:H PV junctions.

$0.3 \mu \mathrm{m}$. The $10 \mathrm{~nm}$ p-doped, $40 \mathrm{~nm}$ gradient reducing (p-) doped and $40 \mathrm{~nm}$ i-type a-SiC:H films were deposited immediately onto the top n-nc-SiO ${ }_{x}$ : $\mathrm{H}$ layers of the three photocathodes, and the processing details are described in Section 2.1.

\subsection{PEC characterization}

PEC characterization was carried out in a three-electrode configuration: (i) the a-SiC:H photocathode with an active area of $0.283 \mathrm{~cm}^{2}$ (an illuminated hole of $6 \mathrm{~mm}$ diameter) as the working photocathode, (ii) a coiled Pt wire as the counter electrode, and (iii) a $\mathrm{Ag} / \mathrm{AgCl}$ electrode (XR300, saturated $\mathrm{KCl}$ solution, Radiometer Analytical) as the reference electrode. 0.1 $\mathrm{M}\left(\mathrm{mol} \mathrm{L}{ }^{-1}\right)$ sulfamic acid $\left(\mathrm{H}_{3} \mathrm{NSO}_{3}\right)$ was utilized as the electrolyte, buffered to $\mathrm{pH} \sim 3.75$ by potassium biphthalate (KHP). White light photocurrent measurements were performed under simulated AM 1.5 solar illumination $\left(100 \mathrm{~mW} \mathrm{~cm}^{-2}\right)$ with a NEWPORT Sol3A Class AAA solar simulator (type 94023A-SR3).

\subsection{ASA simulation}

ASA (Advanced Semiconductor Analysis) is a program developed by the PVMD group in TU Delft using MATLAB and C++. It is designed for the optical and electrical simulation of devices based on amorphous and crystalline semiconductors. The ASA program solves the basic semiconductor equations in one dimension (the Poisson equation and two continuity equations for electrons and holes). In this work, we built optical models in ASA to simulate the absorption spectrum of each PEC or PV junction illuminated by the AM 1.5 spectrum transmitted through the electrolyte and quartz window. The ellipsometry measured wavelength-dependent reflective index, $n(\lambda)$, extinction coefficient, $k(\lambda)$ and thicknesses of the layers were the optical input data for the simulation. The glass substrates with integrated micro-textured photonic structures were considered as the back reflector in the model as well. The short-circuit current density of each junction was integrated from the absorption spectrum and the AM 1.5 solar spectrum.

\section{Results and discussions}

\subsection{Boron doping profiling in the a-SiC:H photocathode}

An a-SiC:H electrode generally has a fast charge carrier recombination and a short diffusion length due to high defect densities. ${ }^{29}$ Further Ohmic losses can be significant for thick films. The charge carrier recombination limits the maximum splitting of the quasi-Fermi levels in the a-SiC:H PEC junction, and subsequently results in larger effective overpotentials. The thicker the a-SiC:H film, the more the charge carrier collection is limited by charge carrier recombination.

The effect of charge carrier recombination is demonstrated using $j-V$ curves of the a-SiC:H based photocathodes measured under AM $1.5\left(100 \mathrm{~mW} \mathrm{~cm}^{-2}\right)$ standard test conditions in the three-electrode configuration as shown in Fig. 2. Three PEC electrodes are considered, and all involve a p-a-SiC:H (boron (B)doped) layer interface with an i-a-SiC:H layer with a total thickness of $90 \mathrm{~nm}$, where the intrinsic (not intentionally doped, more strictly speaking) a-SiC:H faces the electrolyte. Cartoons of the three are shown in Fig. 2. The first junction, Fig. 2(a), consists of a thin p-a-SiC:H layer $(10 \mathrm{~nm})$ with an 80 nm thick i-a-SiC:H layer. The p/i junction separates the light-
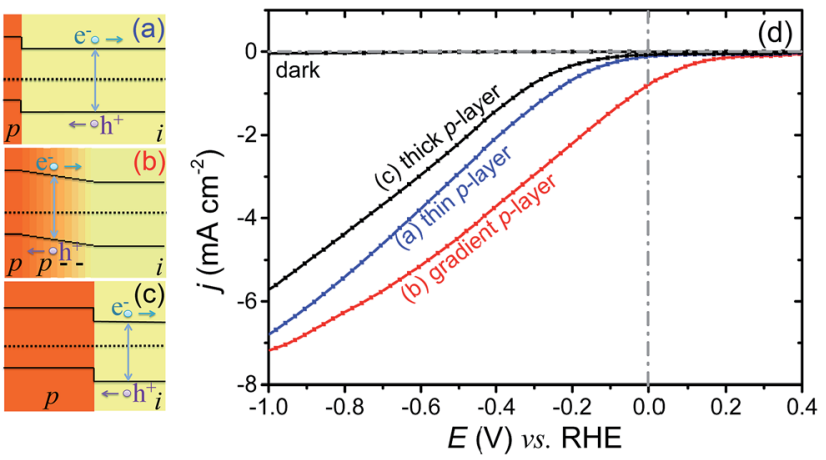

Fig. 2 Schematic presentations demonstrating the variation of the doping concentration with thickness in the p/i junction $(a-c)$. Threeelectrode AM $1.5 j-V$ curves with and without gradient B doping (d). 
excited charge carriers and generates a light-induced potential. While drift is the dominant transport mechanism for the lightexcited charge carriers in the depletion zone in the p-a-SiC:H layer, diffusion is the dominant transport mechanism in the i-layer. Since the i-layer is much thicker, the charge carrier transport in the PEC is most likely to be dominated by diffusion. As a result, charge carrier collection under light exposure is limited by recombination in the i-layer for this configuration (Fig. 2(a)). Thus a thin p-layer configuration resulted in a negative photocurrent onset potential ( $0 \mathrm{~V} v s$. RHE), as seen in the $j-V$ curve in Fig. 2 (d) (blue curve).

In the second device (Fig. 2(b)), the thickness of the depletion zone is increased using a p-type gradient boron doping layer between the $\mathrm{p}$ - and i-layers. This enlarges the area where drift is the dominant mechanism of charge transport and enhances charge carrier collection, as fewer charge carriers are lost due to recombination in the diffusion-dominated region of the junction. This junction consists of a $10 \mathrm{~nm}$ thick p-a-SiC:H (B) layer, a $40 \mathrm{~nm}$ thick gradient layer in which the concentration of boron doping (herein called "p-") was reduced from the value in the p-layer to $0 \%$ in 10 steps of $4 \mathrm{~nm}$ each, and a $40 \mathrm{~nm}$ thick i-a-SiC:H layer. Due to improved charge carrier collection, the onset potential shifts anodically by $\sim 200 \mathrm{mV}$ as compared to the thin p-layer configuration (Fig. 2(a)).

To exclude the possibility that the enhancement is instead caused by a thicker doped layer and not the gradient doping, a "thick p-layer" configuration (Fig. 2(c)), which consists of a 50 $\mathrm{nm}$ thick p-a-SiC:H (B) layer and a $40 \mathrm{~nm}$ thick i-a-SiC:H layer, has been tested as well. For this configuration the onset potential shifts cathodically, showing that now the recombination in the more defective p-layer dominates over the recombination in the thinner i-layer. We can therefore conclude that the improvement that we observed is indeed caused by the introduction of gradient doping in our film.

The "gradient p-layer" photocathode has a current density in the order of $\sim-0.8 \mathrm{~mA} \mathrm{~cm} \mathrm{~cm}^{-2}$ at $0 \mathrm{~V} v s$. RHE. This is $33 \%$ improvement compared to the much thicker $(\sim 220 \mathrm{~nm})$ a-SiC:H photocathode with a photocurrent density of $\sim-0.6 \mathrm{~mA} \mathrm{~cm}^{-2}$ at $0 \mathrm{~V} v s$. RHE reported by Zhu et al. ${ }^{26} \mathrm{At}-1.0 \mathrm{~V} v s$. RHE the a-SiC:H photocathode in Fig. 2 has a current density of $-7.2 \mathrm{~mA} \mathrm{~cm}^{-2}$ considering its thickness of only $90 \mathrm{~nm}$. Although the potential of $-1 \mathrm{~V} v s$. RHE is of little relevance, this photocurrent is $100 \%$ higher than that of any other reported a-SiC:H photocathodes. ${ }^{26}$

\subsection{Monolithic PEC/PV cathode}

As illustrated in Fig. 2, although the a-SiC:H photocathode can generate a high photocurrent density at negative potentials $(\leq-1 \mathrm{~V} v s$. RHE), it only generates a current density of $-0.8 \mathrm{~mA}$ $\mathrm{cm}^{-2}$ at $0 \mathrm{~V} v s$. RHE. The challenge is therefore to anodically shift the onset potential of the $j-V$ curves to more positive potentials. Herein we achieve this shift by the monolithic integration of a TF-Si PV device between the textured substrate at the back contact and the photocathode. The extra photovoltage from the PV junction(s) is achieved to provide the overpotential at the semiconductor/electrolyte interface. To illustrate this mechanism, the corresponding energy band diagram of an a-SiC:H(PEC)/a-Si:H(PV)/nc-Si:H(PV) photocathode is shown in Fig. 3. The flat band potential is characterized by electrochemical impedance spectroscopy (EIS) as illustrated in Fig. S4 and S5 in the ESI. $\dagger$

To successfully integrate a PV cell into a tandem PEC/PV cathode, the PV device needs to meet several requirements. Firstly, the spectral utilization of the photocathode and solar cells should be equally distributed among all the PEC and PV junctions. Secondly, the voltage at the operating point $\left(V_{\mathrm{OP}}\right)$ of the solar cells should be large enough to overcome the overpotential. Based on these considerations, we integrated three types of TF-Si solar cells with the a-SiC:H, i.e., a single junction a-Si:H solar cells $\left(V_{\mathrm{OC}} \sim 0.9 \mathrm{~V}\right)$ (photocathode $\mathrm{A}$ ), a micromorph (a-Si:H/nc-Si:H, $V_{\text {OC }} \sim 1.4 \mathrm{~V}$ ) solar cell (photocathode B) and a nano-crystalline double junction (nc-Si:H/nc-Si:H, $V_{\mathrm{OC}} \sim 1.0 \mathrm{~V}$ ) solar cell (photocathode $\mathrm{C}$ ). An illustrative sketch of photocathode $\mathrm{C}$ is shown in Fig. 1(a).

To guarantee device-grade materials and high spectral utilization, we introduce a special substrate at the back contact for the monolithically integrated photocathodes. Textured substrates are the conventional approach to enhance light trapping in PV devices. ${ }^{\mathbf{3 0 , 3 1}}$ However, nc-Si:H is highly sensitive to an extreme texture, as the texture initiates the growth of defect-rich filaments above sharp valleys. ${ }^{32}$ These filaments significantly reduce the fill factor (FF), open circuit voltage and current density of the PV junctions. ${ }^{32,33}$ To prevent the incorporation of defect-rich filaments and to allow the integration of thick high quality nc-Si:H junctions in our PEC/PV cathodes, we use state-of-the-art glass substrates with integrated microtextured photonic structures. These photonic structures are obtained by wet-etching a sacrificial ITO layer on Corning glass, resulting in craters with diameters on the order of $10 \mu \mathrm{m}$ and depths of $2 \mu \mathrm{m}$. The back-reflector, PV and PEC junctions are deposited on top and adopt the micro-textured photonic structures. As demonstrated in the SEM image in Fig. 1(b), the glass substrate with micro-textured photonic structures allows the growth of highly dense nc-Si:H material, without defect-rich

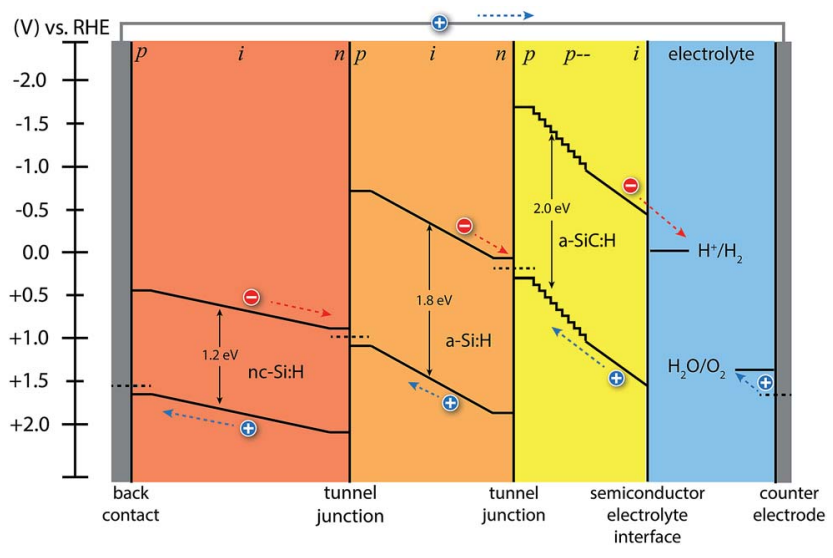

Fig. 3 A band diagram illustration of the multi-junction a-SiC:H/ a-Si:H/nc-Si:H cathode under non-biased illumination conditions. The band edges of the outermost layer $(\mathrm{a}-\mathrm{SiC}: \mathrm{H})$ are assumed to be pinned at the semiconductor/electrolyte interface. 
filaments. This structure guarantees high $V_{\mathrm{OC}}$ values, current densities and excellent light trapping for the PEC/PV cathodes.

To determine the performance of the PEC/PV cathodes, the samples are immersed in the $\mathrm{H}_{3} \mathrm{NSO}_{3}$ electrolyte buffered at pH 3.75 and are illuminated by a solar simulator (AM 1.5, $100 \mathrm{~mW} \mathrm{~cm}^{-2}$ ). In a three-electrode configuration, the ability of the photocathode to drive the hydrogen evolution reaction is evaluated. The PEC characterizations of the a-SiC:H photocathodes integrated with the three different TF-Si solar cells are shown in Fig. 4(a)-(c). The current density in the dark for all the samples is negligible (black dashed curves).

The introduction of an a-Si:H single-junction solar cell (photocathode A) shifts the onset potential anodically by $\sim 0.8 \mathrm{~V}$ (green curve in Fig. 4(a)). This shift is in agreement with typical values for the operating voltage $V_{\mathrm{OP}}$ of a single a-Si:H PV junction. For photocathode B with the a-Si:H/nc-Si:H solar cell (red curve in Fig. 4(b)), the anodic shift of the onset potential is $\sim 1.2$ $\mathrm{V}$, which again corresponds to typical values for the operating voltage $V_{\mathrm{OP}}$ of an a-Si:H/nc-Si:H solar cell. For the doublejunction nc-Si:H/nc-Si:H cell, photocathode $\mathrm{C}$, the onset potential of the photocathode is approximately $1.0 \mathrm{~V}$ (blue curve in Fig. 4(c)). In contrast to the other two photocathodes, this shift is larger than the typical operating point of a nc-Si:H/ nc-Si:H double PV junction and is close to the typical $V_{\mathrm{OC}}$ values of $\sim 1.0 \mathrm{~V}$ for such cells. This implies that the a-SiC:H is the current limiting junction in photocathode C. Under such operating conditions the PV junctions operate at voltages close

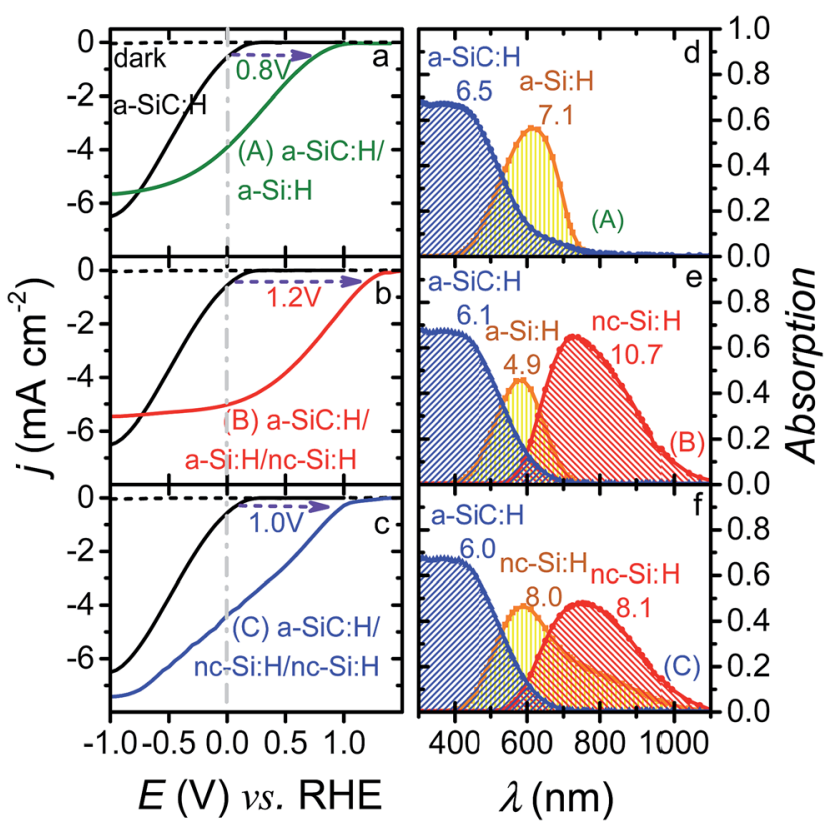

Fig. 4 (a)-(c) AM 1.5 photocurrent density-voltage curves of photocathodes integrated with various PV solar cells. The dark currents of each sample are shown as dashed lines. (d)-(f) Spectral utilization in various PEC/PV configurations by ASA simulation. The numbers below a-SiC: $\mathrm{H}$ indicate the maximum current density $\left(\mathrm{mA} \mathrm{cm}^{-2}\right)$ integrated from the absorption spectrum of the a-SiC:H layers, and the numbers below the solar cell junction (a-Si:H and/or nc-Si:H) indicate the shortcircuited photocurrent density $\left(\mathrm{mA} \mathrm{cm}^{-2}\right)$ of each junction. to their open circuit voltage $V_{\text {OC }}$. The agreement between the anodic shifts in the $j-V$ curve and the $V_{\mathrm{OP}}$ or $V_{\mathrm{OC}}$ values of the three solar cell devices shows that no additional potential barriers are created due to the monolithic integration of PV junction(s) with the PEC junction.

Since all the current densities of the three photocathodes are close to saturation at $-1 \mathrm{~V}$ vs. RHE, we define a saturation current density, $J_{\text {sat }}$, as the $j$ measured at $-1 \mathrm{~V} v s$. RHE. Since the PEC and PV junctions in the monolithically integrated photocathodes are in-series-connected, the $J_{\text {sat }}$ is determined by the current density of the limiting junction. The highest $J_{\text {sat }}$ among the three PEC/PV cathodes is $-7.3 \mathrm{~mA} \mathrm{~cm}^{-2}$, achieved by the aSiC:H/nc-Si:H/nc-Si:H (photocathode C) structure. The $J_{\text {sat }}$ values in the cases of a-SiC:H/a-Si:H/nc-Si:H (photocathode B) and a-SiC:H/a-Si:H (photocathode A) are relatively lower: -5.3 and $-5.8 \mathrm{~mA} \mathrm{~cm}^{-2}$, respectively.

\subsection{Analysis of spectral utilization}

In a monolithically interconnected photocathode, it is highly challenging to experimentally determine the quantum efficiency of each individual junction. Therefore, we simulate the spectral utilization of these junctions using an in-house developed Advance Semiconductor Analysis (ASA) software $^{34}$ to support our measurements and study the potential current densities of these photocathodes. The ASA software is an established tool to model Si-based solar devices and excellent agreement between experiments and simulations has been demonstrated. Based on this we can state that the systematic relative error in the calculated current density is not higher than $10 \% .^{35-37}$ Optical models of multi-layers representing the various PEC/PV configurations are constructed in ASA. Measured wavelength-dependent reflective index, $n(\lambda)$, extinction coefficient, $k(\lambda)$ and thicknesses of the layers are used as the optical input data for the simulation. The wavelength-dependent reflectance $R(\lambda)$ and transmittance $T(\lambda)$ simulations are then simulated in the three PEC/PV cathodes: a-SiC:H/a-Si:H (photocathode A), a-SiC:H/a-Si:H/nc-Si:H (photocathode B), and a-SiC:H/nc-Si:H/nc-Si:H (photocathode C). The absorption spectrum $A(\lambda)$ for each junction can be calculated as

$$
A(\lambda)=1-R(\lambda)-T(\lambda)
$$

and the simulated results are illustrated in Fig. 4(d)-(f).

For photocathode A, the ASA simulations show that the a-SiC:H PEC junction is almost current matched with the a-Si:H PV junction (6.5 vs. $7.1 \mathrm{~mA} \mathrm{~cm}^{-2}$ ). The maximum total spectral utilization (sum of the absorption of each individual junction) is determined by the junction with the lowest band gap. In photocathode A, this is the a-Si:H cell. Therefore, photocathode A has a total current density of $13.6 \mathrm{~mA} \mathrm{~cm}^{-2}$ which is already close to that of a typical state-of-the-art single a-Si:H PV junction with current densities of $15-16 \mathrm{~mA} \mathrm{~cm}^{-2}$ under $100 \mathrm{~mW} \mathrm{~cm} \mathrm{~m}^{-2}$ AM 1.5 conditions. The maximum total spectral utilization of photocathodes $\mathrm{B}$ and $\mathrm{C}$ is limited by the low band gap of the nc-Si:H junction(s). The total spectral utilization of photocathode $\mathrm{B}$ is $21.7 \mathrm{~mA} \mathrm{~cm}{ }^{-2}$ which is a value approaching the current density generated in a state-of-the-art single nc-Si:H PV 
junction of $25-31 \mathrm{~mA} \mathrm{~cm} \mathrm{~cm}^{-2} \cdot{ }^{38}$ However, the overlap of the spectral response of the a-Si:H PV junction with that of the a-SiC:H PEC and nc-Si:H PV junction is significant, making the a-Si:H junction the current limiting one $\left(\sim 5 \mathrm{~mA} \mathrm{~cm}^{-2}\right)$. Photocathode $\mathrm{C}$ is the only configuration in which the photocathode is strongly current limiting $\left(\Delta J=2 \mathrm{~mA} \mathrm{~cm}^{-2}\right)$. This supports the earlier mentioned observation that the PV junctions of photocathode $\mathrm{C}$ are forced to operate at a voltage close to the $V_{\mathrm{OC}}$. This simulation shows that there still is plenty of room to improve the spectral utilization of photocathode $\mathrm{C}$.

We then compare the photocurrent densities of photocathodes measured at $0 \mathrm{~V} v s$. RHE $\left(J_{0}\right)$. The $J_{0}$ at this catalyst-free photocathode is the highest for photocathode B with $J_{0}=-5.1$ $\mathrm{mA} \mathrm{cm}{ }^{-2}$, as compared to those for photocathode $\mathrm{A}\left(J_{0}=-4.0\right.$ $\left.\mathrm{mA} \mathrm{cm}{ }^{-2}\right)$ and photocathode $\mathrm{C}\left(J_{0}=-4.5 \mathrm{~mA} \mathrm{~cm}^{-2}\right)$. The results demonstrate that the value for $J_{0}$ of these PEC/PV cathodes is a competition between maximum utilization of the band gap energy of the PV device to facilitate the anodic shift and the maximum spectral utilization to facilitate the highest current densities. High band gap materials like a-Si:H provide high voltages but low currents, whereas low band gap materials like nc-Si:H provide low voltages and high currents. To quantify the performance of the photocathodes further, we define a second external parameter, i.e. the maximum efficiency of the photocathode $\eta_{\mathrm{PC}}$ as: ${ }^{39}$

$$
\eta_{\mathrm{PC}}=\frac{-j_{\max }\left(V_{\max }-V_{\mathrm{RHE}}\right)}{I_{0}} \times 100 \%
$$

where $j_{\max }$ and $V_{\max }$ are the current density and voltage at the maximum power point, respectively. We find $\eta_{\mathrm{PC}}=2.1 \%, 1.3 \%$ and $0.8 \%$ for photocathodes A, B and C, respectively, which are promising results considering that these a-SiC:H photocathodes are not deposited with any HER catalysts or passivation layers. By depositing $\mathrm{Ru}$ nanoparticles as the catalysts, an a-SiC:H/a-Si:H/a-Si:H photocathode can indeed enhance the $\eta_{\mathrm{PC}}$ from $0.125 \%$ to $1.9 \%$, as reported by Zhu et al. ${ }^{28}$ Therefore, next to further improving carrier collection, the catalytic activity can be significantly improved by depositing HER catalysts on the aSiC:H. This will result in a large additional anodic shift and significantly higher values for $\eta_{\mathrm{PC}}$.

Based on these results, the realistic potential of the spectral utilization of these PEC/PV cathodes can be estimated. If only a single a-Si:H PV junction is integrated with the a-SiC:H photocathode, the theoretical maximum $J_{\text {sat }}$ value is $24 / 2=12 \mathrm{~mA}$ $\mathrm{cm}^{-2}$, assuming that all the photons in the solar spectrum (until $800 \mathrm{~nm}$ ) are converted into electron-hole-pairs and the current is equally distributed between the a-SiC:H photocathode and the a-Si:H solar cell. However, a more realistic approach would be to take the highest spectral utilization for an a-Si:H singlejunction of $18 \mathrm{~mA} \mathrm{~cm}^{-2}$ achieved to date, ${ }^{40}$ which would imply a $J_{\text {sat }}$ of $\sim 9 \mathrm{~mA} \mathrm{~cm}^{-2}$. When the double-junction solar cell with the nc-Si:H material is integrated with the a-SiC:H photocathode, the theoretical maximum $J_{\text {sat }}$ value can achieve $42 / 3=$ $14 \mathrm{~mA} \mathrm{~cm}^{-2}$. In view of the nc-Si:H PV junction with the highest current utilization achieved to date $\left(\sim 32 \mathrm{~mA} \mathrm{~cm}^{-2}\right)$, this overall photocathode photocurrent density would be $10.7 \mathrm{~mA} \mathrm{~cm}$. This simple analysis therefore shows that a $13 \%$ efficient solar- to-hydrogen conversion device is well within reach with the combination of an a-SiC:H photocathode and a TF-Si solar cell.

\subsection{Stability of a TF-Si based PEC/PV cathode}

An advantage of the a-SiC:H photocathode is its relatively longterm stability in an acidic medium. As reported by $\mathrm{Hu}$ et al., their a-SiC:H photocathode showed a stable photocurrent density after $800 \mathrm{~h}$ illumination in $\mathrm{pH} 0.3 \mathrm{H}_{2} \mathrm{SO}_{4}$ acid. ${ }^{22}$

Herein we also show the stability of our a-SiC:H photocathode in a pH 3.75 sulfamic acid electrolyte. Fig. 5(a) shows the chronoamperometry measurement of photocathode $\mathrm{B}$ biased at $0 \mathrm{~V}$ vs. RHE. We observe a slight current density enhancement in the first 2 min of illumination, which is a result of the acidic electrolyte etching the thin native oxide layer on the i-a-SiC:H surface. The following "periodical" fluctuation is caused by repetitive accumulation and dislodging of $\mathrm{H}_{2}$ bubbles at the photocathode surface. Nevertheless, the photocurrent is relatively stable over the course of an hour. A photograph of photocathode A before and after the one-hour measurement is shown in Fig. 5(b), and the purple surface of the sample remains unchanged after immersing in the acidic electrolyte for one hour.

The photocurrent density of $-5.1 \mathrm{~mA} \mathrm{~cm}^{-2}$ at $0 \mathrm{~V} v s$. RHE is the highest photocurrent reported for any a-SiC:H photocathode. The record photocurrent is achieved without catalysts

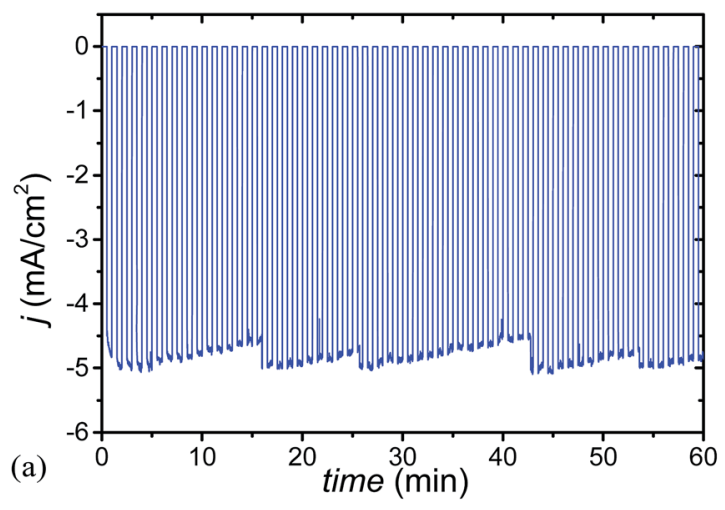

(b)

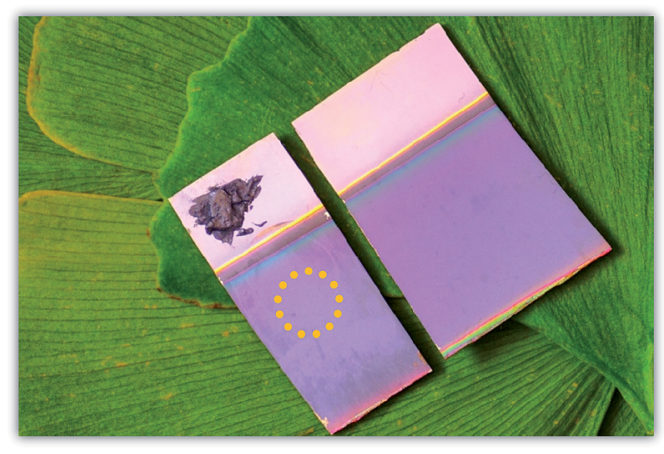

Fig. 5 The photocurrent density of the a-SiC:H/a-Si:H/nc-Si:H photocathode monitoring measurement in a pH 3.75 acid illuminated by an AM 1.5 chopped spectrum for 1 hour (a). The surface of the photocathode remains unchanged before (right) and after (left) $1 \mathrm{~h}$ measurement (b). The orange dot circle with a diameter of $6 \mathrm{~mm}$ indicates the active area of the photocathode $\left(0.283 \mathrm{~cm}^{2}\right.$ in total area). 
or passivation layers added to the a-SiC:H photocathode. Combined with its stability in acidic solution, our results demonstrate the high potential of thin-film a-SiC:H as a photocathode.

\section{Conclusions}

A catalyst- and precious-metal-free a-SiC:H(PEC)/a-Si:H(PV)/ nc-Si:H(PV) water-splitting photocathode with a photocurrent density of $-5.1 \mathrm{~mA} \mathrm{~cm} \mathrm{~cm}^{-2}$ at $0 \mathrm{~V} v s$. RHE and a photocathode efficiency of $2.1 \%$ has been achieved. This PEC/PV cathode based on earth-abundant materials is highly stable for over 1 hour in an acidic electrolyte under simulated AM 1.5 illumination. The overpotential of an a-SiC:H PEC photocathode is reduced by the introduction of gradient boron doping in the a-SiC:H PEC junction, enhancing the charge carrier collection. Dense TF-Si layers exhibiting electrical performance and high spectral utilization in the PEC and PV junctions are achieved by using state-of-the-art glass substrates with integrated microtextured photonic structures. By using three different monolithically PEC/PV integrated photocathode configurations, the extent of the PV-induced anodic shift is demonstrated. The balance between the anodic shift and the optimized spectral utilization of the PEC/PV configuration is further studied using simulations of the spectral utilization of various PEC/PV cathodes. Based on the presented work, a-SiC:H/TF-Si based PEC/PV cathodes with current densities above $10 \mathrm{~mA} \mathrm{~cm}^{-2}$ are within reach.

\section{Acknowledgements}

The authors would like to thank Guangtao Yang from PVMD group in TU Delft for assistance with substrate preparation, Dr Feng Zhu from MVSystems Inc. and Dr Bruce S. Brunschwig from the Molecular Materials Research Center (MMRC) at California Institute of Technology for helpful scientific discussions. Financial support from the VIDI project (granted to Dr A. H. M. Smets) by NWO-STW is gratefully acknowledged. This research is financed in part by the BioSolar Cells open innovation consortium (W. A. Smith and I. A. Digdaya), supported by the Dutch Ministry of Economic Affairs, Agriculture and Innovation. Z. Huang and R. Liu are supported by the Joint Center for Artificial Photosynthesis, a DOE Energy Innovation Hub, supported through the Office of Science of the U.S. Department of Energy under Award Number DE-SC0004993.

\section{Notes and references}

1 L. Han, F. F. Abdi, P. Perez Rodriguez, B. Dam, R. van de Krol, M. Zeman and A. H. M. Smets, Phys. Chem. Chem. Phys., 2014, 16, 4220-4229.

2 L. Han, F. F. Abdi, R. van de Krol, R. Liu, Z. Huang, H.-J. Lewerenz, B. Dam, M. Zeman and A. H. M. Smets, ChemSusChem, 2014, 7, 2832-2838.

3 F. F. Abdi, L. Han, A. H. M. Smets, M. Zeman, B. Dam and R. van de Krol, Nat. Commun., 2013, 4, 2195.
4 J. Brillet, J. H. Yum, M. Cornuz, T. Hisatomi, R. Solarska, J. Augustynski, M. Graetzel and K. Sivula, Nat. Photonics, 2012, 6, 823-827.

5 A. E. Delahoy, S. C. Gau, O. J. Murphy, M. Kapur and J. O. M. Bockris, Int. J. Hydrogen Energy, 1985, 10, 113-116.

6 N. Gaillard, Y. Chang, J. Kaneshiro, A. Deangelis and E. L. Miller, P. Soc. Photo-Opt. Ins., 2010, 7770, 77700V.

7 O. Khaselev and J. A. Turner, Science, 1998, 280, 425-427.

8 S. Licht, J. Phys. Chem. B, 2001, 105, 6281-6294.

9 E. L. Miller, B. Marsen, D. Paluselli and R. Rocheleau, Electrochem. Solid-State Lett., 2005, 8, A247-A249.

10 S. Y. Reece, J. A. Hamel, K. Sung, T. D. Jarvi, A. J. Esswein, J. J. H. Pijpers and D. G. Nocera, Science, 2011, 334, 645-648.

11 R. E. Rocheleau, E. L. Miller and A. Misra, Energy Fuels, 1998, 12, 3-10.

12 Y. Yamada, N. Matsuki, T. Ohmori, H. Mametsuka, M. Kondo, A. Matsuda and E. Suzuki, Int. J. Hydrogen Energy, 2003, 28, 1167-1169.

13 L. Han, F. F. Abdi, R. van de Krol, B. Dam, M. Zeman and A. H. M. Smets, in 40th IEEE Photovoltaic Specialist Conference (PVSC), IEEE, 2014, pp. 3083-3086.

14 E. L. Miller, R. E. Rocheleau and X. M. Deng, Int. J. Hydrogen Energy, 2003, 28, 615-623.

15 E. L. Miller, R. E. Rocheleau and S. Khan, Int. J. Hydrogen Energy, 2004, 29, 907-914.

16 J. Madan and M. P. Shaw, The Physics and Applications of Amorphous Semiconductors, Academic Press, Inc., California, 1988.

17 C. M. Fortmann, J. O'Dowd, J. Newton and J. Fischer, AIP Conf. Proc., 1987, 157, 103-110.

18 L. H. Hihara, A. Iwane, S. Voss and R. E. Rocheleau, Corros. Sci., 1999, 41, 1403-1417.

19 Y. Tawada, H. Okamoto and Y. Hamakawa, Appl. Phys. Lett., 1981, 39, 237-239.

20 F. Zhu, J. Hu, A. Kunrath, I. Matulionis, B. Marsen, B. Cole, E. L. Miller and A. Madan, Solar Hydrogen and Nanotechnology II, 2007, 6650, S6500.

21 I. Matulionis, F. Zhu, J. Hu, T. Deutsch, A. Kunrath, E. L. Miller, B. Marsen and A. Madan, Solar Hydrogen and Nanotechnology III, 2008, 7044.

22 J. Hu, F. Zhu, A. Kunrath, T. Deutsch and N. Gaillard, MRS Spring Meeting, 2014, pp. 167-170.

23 J. Hu, F. Zhu, I. Matulionis, A. Kunrath, T. Deutsch, L. Kuritzky, E. L. Miller and A. Madan, 23rd European Photovoltaic Solar Energy Conference and Exhibition, 2008, pp. 69-72.

24 I. Matulionis, J. Hu, F. Zhu, J. Gallon, N. Gaillard, T. Deutsch, E. L. Miller and A. Madan, P. Soc. Photo-Opt. Ins., 2010, 7770.

25 A. Stavrides, A. Kunrath, J. Hu, R. Treglio, A. Feldman, B. Marsen, B. Cole, E. L. Miller and A. Madan, Solar Hydrogen and Nanotechnology, 2006, 6340, U149-U156.

26 F. Zhu, J. Hu, I. Matulionis, T. Deutsch, N. Gaillard, A. Kunrath, E. L. Miller and A. Madan, Philos. Mag., 2009, 89, 2723-2739.

27 J. Hu, F. Zhu, I. Matulionis, T. Deutsch, N. Gaillard, E. L. Miller and A. Madan, MRS Spring Meeting, 2009, vol. 1171, pp. 121-126. 
28 F. Zhu, I. Matulionis, N. Gaillard, Y. Chang, J. Hu, J. Gallon and A. Madan, MRS Online Proc. Libr., 2013, 1539.

29 I. Martin, M. Vetter, A. Orpella, J. Puigdollers, A. Cuevas and R. Alcubilla, Appl. Phys. Lett., 2001, 79, 2199-2201.

30 C. Battaglia, C. M. Hsu, K. Soderstrom, J. Escarre, F. J. Haug, M. Charriere, M. Boccard, M. Despeisse, D. T. L. Alexander, M. Cantoni, Y. Cui and C. Ballif, ACS Nano, 2012, 6, 27902797.

31 K. Jager, O. Isabella, L. Zhao and M. Zeman, Phys. Status Solidi C, 2010, 7, 945-948.

32 M. Python, E. Vallat-Sauvain, J. Bailat, D. Domine, L. Fesquet, A. Shah and C. Ballif, J. Non-Cryst. Solids, 2008, 354, 2258-2262.

33 H. Tan, L. Sivec, B. J. Yan, R. Santbergen, M. Zeman and A. H. M. Smets, Appl. Phys. Lett., 2013, 102, 153902.
34 M. Zeman, J. van den Heuvel, M. Kroon, J. Willemen, B. Pieters, J. Krč and S. Solntsev, Advance Semiconductor Analysis User Manual, 2011.

35 K. Jager, M. Fischer, R. A. C. M. M. van Swaaij and M. Zeman, J. Appl. Phys., 2012, 111.

36 K. Jager, M. Fischer, R. A. C. M. M. van Swaaij and M. Zeman, Opt. Express, 2013, 21, A656-A668.

37 K. Jager, D. N. P. Linssen, O. Isabella and M. Zeman, Photonics for Solar Energy Systems V, 2014, vol. 9140.

38 H. Sai, T. Koida, T. Matsui, I. Yoshida, K. Saito and M. Kondo, Appl. Phys. Express, 2013, 6, 104101.

39 Y. Lin, C. Battaglia, M. Boccard, M. Hettick, Z. B. Yu, C. Ballif, J. W. Ager and A. Javey, Nano Lett., 2013, 13, 5615-5618.

40 J. Meier, J. Spitznagel, U. Kroll, C. Bucher, S. Fay, T. Moriarty and A. Shah, Proceedings of 3rd World Conference on Photovoltaic Energy Conversion, 2003, pp. 2801-2805. 